\title{
Patient Safety in Surgery Reviewer acknowledgement 2014
}

Philip F Stahel $^{1 *}$ and Pierre-Alain Clavien ${ }^{2}$

\section{Contributing reviewers}

The Editors of Patient Safety in Surgery would like to thank all our reviewers who have contributed to the journal in Volume 8 (2014).

Negar Ahmadi

Canada

Emma-Louise Aveling

United Kingdom

Fernando Baldy

Brazil

Rodrigo Banegas

United States of America

William Berry

United States of America

Shay Bess

United States of America

Walter L. Biffl

United States of America

Frank Bode

Germany

Nathan Butler

United States of America

Mark Chandler

United States of America

Qi Chen

United States of America

Ted Clarke

United States of America

Muhammad Muzzammil Edhi

Pakistan

\author{
Vincent Eusterman \\ United States of America \\ Johannes Fakler \\ Germany \\ Joan Figueras \\ Spain \\ Ingo Fiss \\ Germany \\ Michael Flierl \\ United States of America \\ Charles Fox \\ United States of America \\ Beat Gloor \\ Switzerland \\ Dieter Hahnloser \\ Switzerland \\ Eric Mark Hammerberg \\ United States of America \\ Jiandong Hao \\ United States of America \\ Markus Huber-Lang \\ Germany \\ Kyros Ipaktchi \\ United States of America \\ Ratna Johari \\ India
}

\author{
Jeffrey Johnson \\ United States of America \\ Jeffry Kashuk \\ United States of America \\ Sebastian Katscher \\ Germany \\ Fernando Kim \\ United States of America
}

\section{Kodi Kojima \\ Brazil}

Christian K. Lackner

Germany

Susan Ladley

United States of America

\section{Philipp Lenzlinger}

Switzerland

\section{Shalin Maheshwari}

India

Matthias Majetschak

United States of America

Cyril Mauffrey

United States of America

Howard Miller

United States of America

Wilson Molina

United States of America

\footnotetext{
* Correspondence: Philip.Stahel@dhha.org

'Denver Health Medical Center, Denver, USA

¿University Hospital Zurich, Zurich, Switerzland
} 
Philipp Mommsen

Germany

John Mukhopadhaya

India

Kenneth Nepple

United States of America

Justin Newman

United States of America

\section{Giuseppe Nigri}

Italy

\section{Lena Nilsson}

Sweden

Andrew Robson

United Kingdom
James Ruskin

United States of America

Stefan Sauerland

Germany

Samuel Smith

United States of America

Wade Smith

United States of America

\section{Olaf Suess}

Germany

Peter Teschendorf

Germany

Per Trobisch

Germany
Todd VanderHeiden

United States of America

Michael Victoroff

United States of America

Robert Waltz

United States of America

Sebastian Weckbach

United States of America

Allison Williams

United States of America

Heather Young

United States of America

Bruce Ziran

United States of America 